\title{
sciendo
}

CIVIL AND ENVIRONMENTAL ENGINEERING REPORTS

E-ISSN 2450-8594

CEER 2019; 29 (3): 164-173

DOI: $10.2478 /$ ceer-2019-0032

Original Research Article

\section{SEISMIC PERFORMANCE EVALUATION OF A PROPOSED BUCKLING-RESTRAINED BRACE FOR RC-MRFS}

\author{
Arunraj EBANESAR ${ }^{1}$, Daniel CRUZE ${ }^{1}$, Ehsan NOROOZINEJAD \\ FARSANGI $^{2 *}$, Vincent Sam Jebadurai SEENIVASAN ${ }^{1}$, \\ Adil Dar MOHAMMAD ${ }^{3}$, Dar ABDUL RASHID ${ }^{4}$, Hemalatha GLADSTON ${ }^{1}$ \\ ${ }^{1}$ Karunya Institute of Technology and Sciences, Coimbatore, India \\ ${ }^{2}$ Graduate University of Advanced Technology, Kerman, Iran \\ ${ }^{3}$ Indian Institute Technology, New Delhi, India \\ ${ }^{4}$ National Institute Technology, Srinagar, J\&K, India
}

\begin{abstract}
This paper presents a novel buckling-restrained brace (BRB) where the inner core is restrained by a concrete infilled Expanded Polystyrene Sheet (EPS) instead of the conventional concrete infilled tube section, to resist inner core buckling. It serves two purposes, firstly, the EPS is a ductile material, which is favourable in terms of seismic performance and, secondly, the outer construction material has better corrosion resistance. Thus, the life of the steel core can be prolonged. In this study, 6 BRB specimens were prepared, of which $3 \mathrm{BRB}$ specimens were infilled with concrete and the remaining 3 BRB specimens with concrete and EPSs, in order to study their performance under cyclic loading. Three different core heights, all with the same core thickness, were adopted. The test results indicate that the load-carrying capacity of this novel BRB is higher than the conventional BRB. Further, the length of the steel tube also affects the strength of the seismic disaster mitigation system. Lastly, a numerical study on a single bay RC frame, with and without BRB subjected to time history analysis, was conducted to check the global performance of this novel system. It was found that the structural responses had substantially decreased.
\end{abstract}

* Corresponding author: Graduate University of Advanced Technology Faculty of Civil and Surveying Engineering, Kerman, Iran, e-mail: noroozinejad@kgut.ac.ir 
Keywords: seismic disaster mitigation, buckling-restrained brace, EPS, local buckling, cyclic load test, RC frame, OpenSees

\section{INTRODUCTION}

In RC buildings, lateral forces are generally resisted by moment frames, particularly beam-column joints. However, their efficiency is always uncertain due to several factors such as congestion of the reinforcement at the beam-column joints, amongst others. Passive control devices like buckling restrained braces (BRB) carry the extensive compressive forces and provide stiffness in tension. Thus, they substantially reduce the effect of seismic forces on the structures. Compared to other passive control systems, the BRB system is economical, dissipates energy, and better-resists lateral forces [1-2]. Compared to a conventional steel bracing system, BRB has exceptional energy absorption characteristics and, to explore the mechanical properties and ductility of such systems, many researchers have conducted analytical and experimental investigations on them [3-4]. Conventionally, the inner steel tube is filled with concrete, and the structural members undergoing tension and compression have been studied by many researchers [5-6]. The BRB system is relied on for many load cases and for resisting lateral forces. The cyclic behaviour of an $\mathrm{H}$-shaped core BRB filled with concrete in a steel tube is unrestrained, the stability and hysteretic performance are novel [7-9]. A concrete-filled steel core is the most commonly used method in BRB and is easy to fabricate at a lower cost [10]. The BRB is wrapped with fibre and experimentally investigated, with the failure of the BRB seen as local buckling in the concrete-filled steel core [11].

This paper presents and investigates a novel BRB design with a debonded gap filled with an EPS sheet at various heights of the outer steel tube. This mechanism provides more ductility and also reduces the potential for core buckling. Six specimens were cast for the experimental investigation in order to understand the cyclic behaviour of this novel system. The load vs. deflection and backbone curve for the 6 specimens are presented. The best-performing BRB in the experimental investigation (BRBE 350), in terms of maximum damping force, was used for further numerical investigation using OpenSees software. A single-story RC frame subjected to time-history analysis was analysed. The response of the frame in terms of force and frame displacement was then studied.

\section{MATERIALS AND METHODS}

\subsection{Expanded Polystyrene Sheet}

The Expanded Polystyrene Sheet (EPS) has a versatile size, shape, and thickness to fulfil the necessary demands. The $R$-Value of the EPS is 4.17 and maintains 
stability. This can act as a thermal barrier to conserve heat in winter and as an air conditioner in the summer. The EPS insulation board is cost-effective, provides high compressive strength when compared with rigid boards, and ensures both thermal and water resistance. The geometric details of various models are shown in Table 1. The physical properties of EPS are as per ASTM C578-08 standards and the thermal conductivity, $k$ factor, is $0.24^{\circ} \mathrm{F} /$ inch. The shear modulus of the sheet is $3171 \mathrm{kN} / \mathrm{m}^{2}$ and the flexural and tensile strengths of the sheet are $241 \mathrm{kN} / \mathrm{m}^{2}$ and $124 \mathrm{kN} / \mathrm{m}^{2}$, respectively.

Table 1. Geometric details of the 6 Models

\begin{tabular}{|l|l|l|l|}
\hline Model & Core length & Tube Section & Core Material \\
\hline BRB 350 - 52 & 500 & $350 \times 30 \times 4$ & Stainless Steel \\
\hline BRB 150-37 & 500 & $150 \times 30 \times 4$ & Stainless Steel \\
\hline BRB 75 -15 & 500 & $75 \times 30 \times 4$ & Stainless Steel \\
\hline BRBE 350 - 62 & 500 & $350 \times 30 \times 4$ & Stainless Steel \\
\hline BRBE 150-48 & 500 & $150 \times 30 \times 4$ & Stainless Steel \\
\hline BRBE 75 - 22 & 500 & $75 \times 30 \times 4$ & Stainless Steel \\
\hline
\end{tabular}

\subsection{Stainless Steel}

SAE 304 stainless steel with a wall thickness of $6 \mathrm{~mm}$ was used which contains both chromium and nickel metals as the main non-ferrous constituents. It is an austenite steel with a higher corrosion resistance than regular steel and is widely used due to the ease of rolling into various shapes.

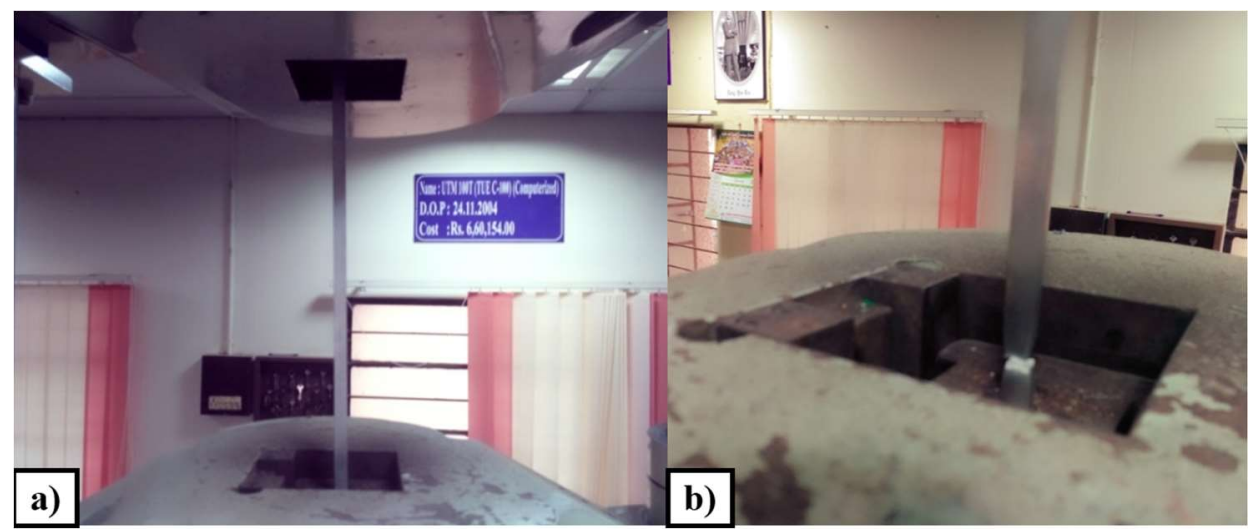

Fig. 1. a) Experiment setup in UTM b) Failure of Stainless Steel

Figures 1 and 2 show the test setup for the tensile test and the load vs. displacement curve for the tensile test, respectively. 


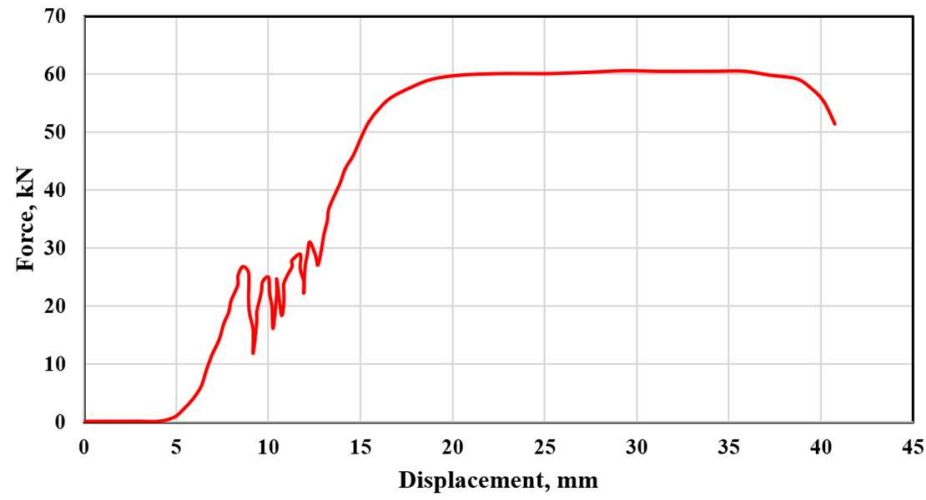

Fig. 2. Tensile test result; Load vs. Deflection

\subsection{Buckling-Restrained Brace}

Six models of BRB specimens were fabricated with varying core lengths, whereby three of them were cast without a debonding gap and the remaining three with a debonding gap. In models with a debonding gap, EPS sheet is used as a filler material for high ductility and to reduce local buckling of the core. The schematic representation of BRB is depicted in Figure 3. The thickness of the EPS is $5 \mathrm{~mm}$, the length of the steel tubes is $350 \mathrm{~mm}, 150 \mathrm{~mm}$, and $75 \mathrm{~mm}$. In the experimental setup, BRB fixtures are placed at both ends and cyclic loading was applied for all casted specimens. The casted specimens are shown in Fig. 4.

a)

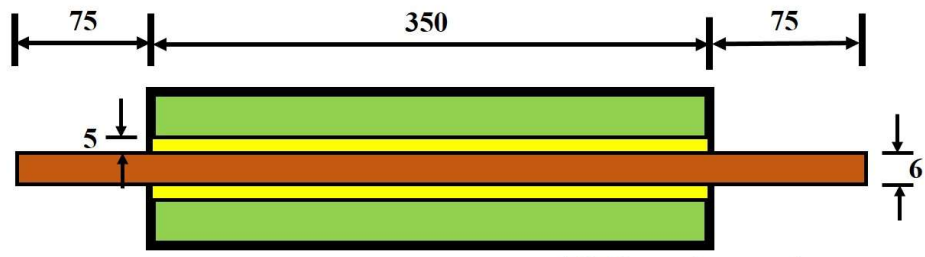

All Dimensions are in mm
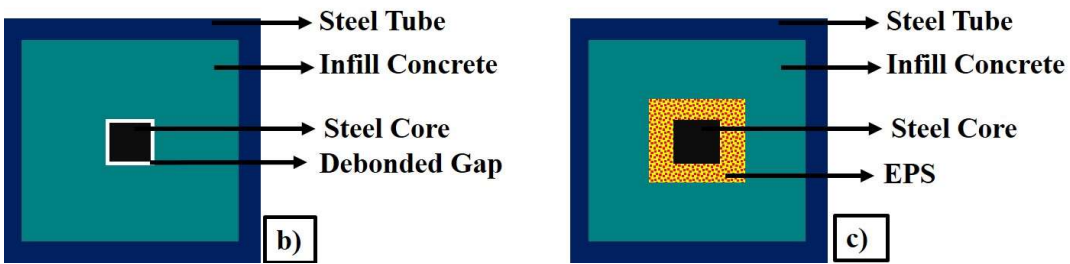

Fig. 3. a) Schematic representation BRB b) Conventional BRB c) Proposed BRB 


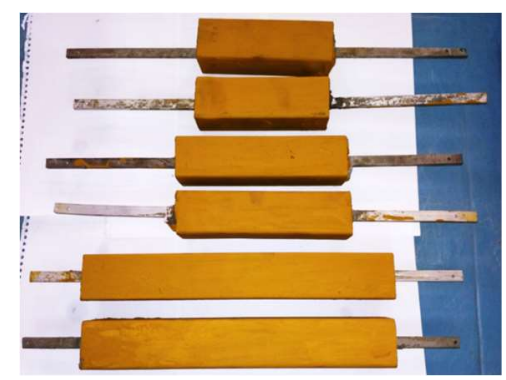

Fig. 4. Six casted BRB specimens with and without EPS at various tube length

\subsection{Experimental Setup}

The testing of the BRB specimens was carried out on a servo-controlled mechanical testing system (MTS) of capacity $1000 \mathrm{kN}$, as shown in Figure 5. The specimen was fixed at both ends in the UTM, as shown in Figure 5. The loads were measured using a self-load cell attached in the force accelerometer. The data acquisition system adopted measures both the load as well as the displacement. The cyclic load was applied in the load-controlled mode.

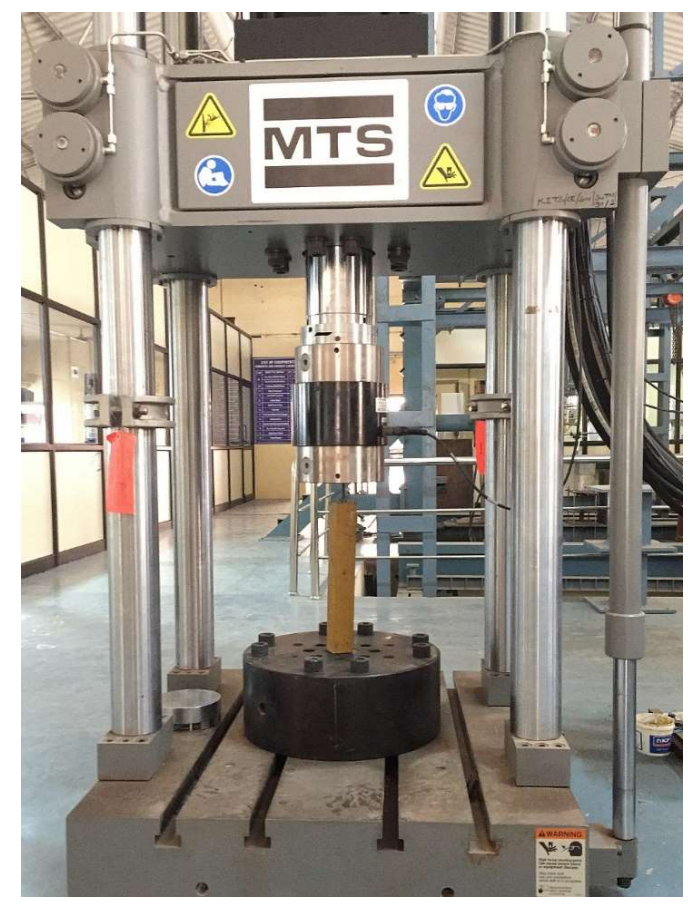

Fig. 5. Experimental setup - UTM 


\section{RESULTS AND DISCUSSION}

From the conducted tests, it was observed that all three specimens with EPS experienced less local buckling in the core. The load-carrying capacities of the novel BRB specimens viz., BRBE 350, BRBE 150, BRBE 75 were comparatively higher than the conventional ones. The maximum load-carrying capacity was observed in BRBE 350, being $62.2 \mathrm{kN}$, as shown in Figure 6 (a). Compared to specimen BRB 350, the novel specimen BRBE 350 showed an improvement of $15.4 \%$ in load-carrying capacity. Similarly, an improvement of $20.24 \%$ and $44 \%$ was observed in BRBE 150 and BRBE 75 when compared to their respective conventional BRBs, as shown in Figures 6 (b \& c), respectively. From the backbone curves, the force exhibits the properties of a bilinear model. The tension strength behaviour of BRB without EPS is shown in Figure 7 (a). The tensile strength and stiffness under compression are larger than those under tension. The behaviour of BRBs with EPS is shown in Figure 7 (b).

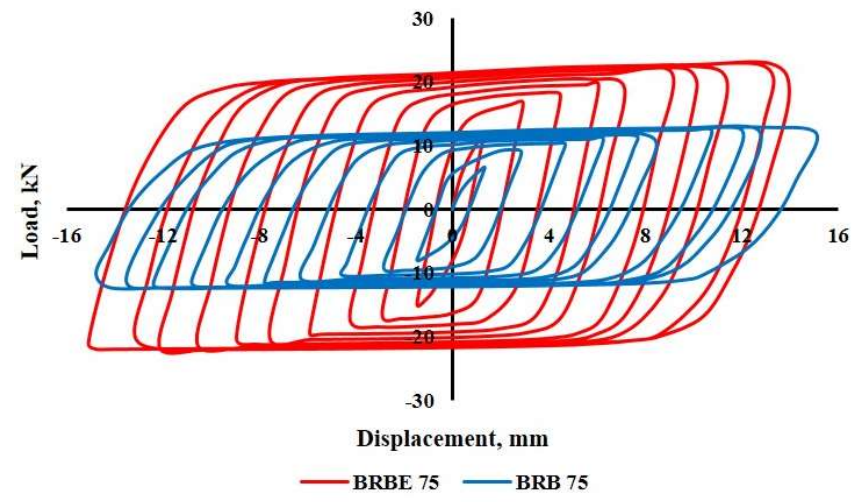

Fig. 6. a) Load vs. Displacement for BRBE 75 and BRB 75

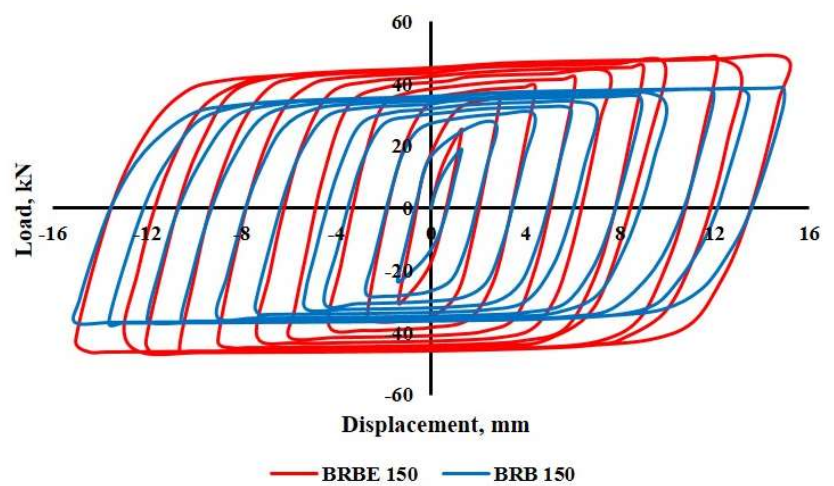

Fig. 6. b) Load vs. Displacement for BRBE 150 and BRB 150 


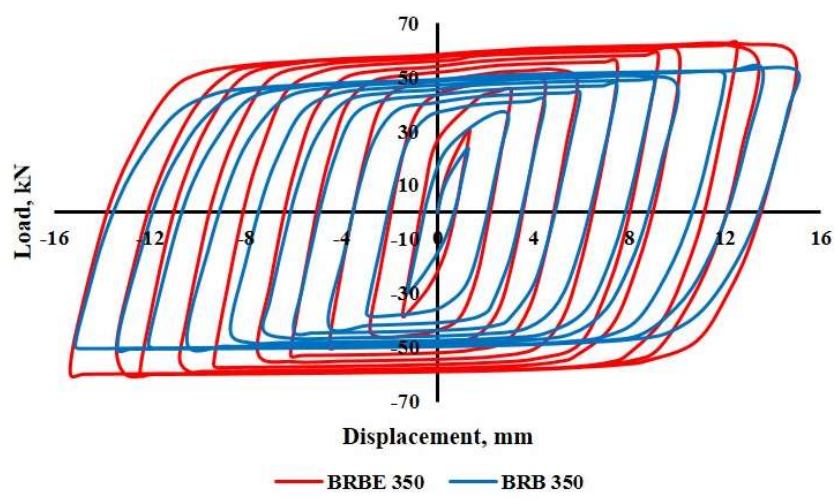

Fig. 6. c) Load vs. Displacement for BRBE 350 and BRB 350

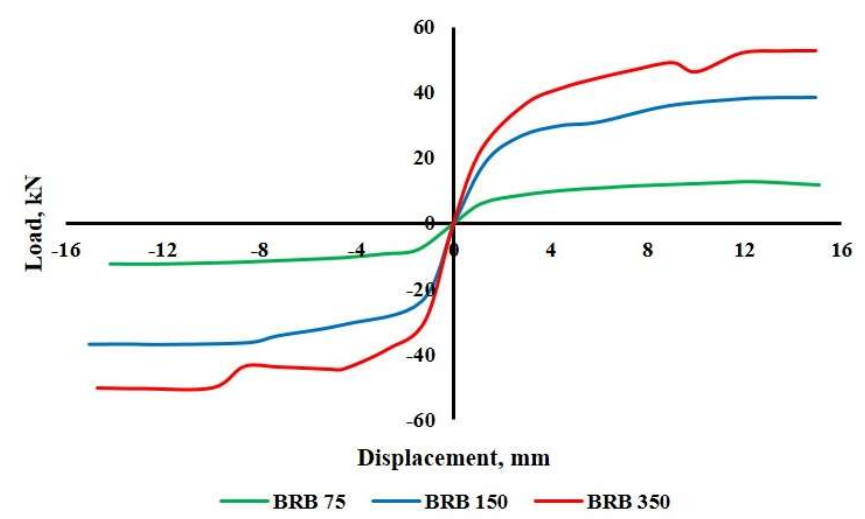

Fig. 7. a) Backbone curve of BRB without EPS

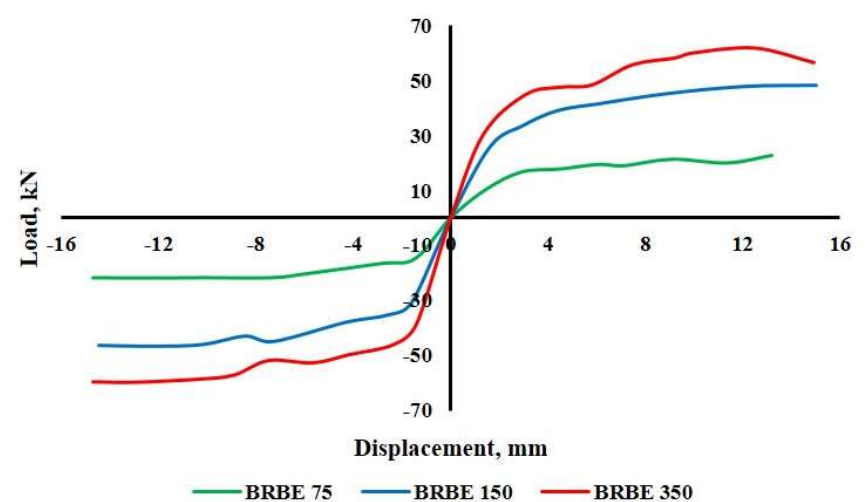

Fig. 7. b) Backbone curve with EPS 


\subsection{Numerical Investigation}

A single bare reinforced concrete (RC) frame of $3 \mathrm{~m} \mathrm{x} 3 \mathrm{~m}$ size was simulated in OpenSees platform [12]. The beam and column physical properties were assigned in the TCL script of the program, note that the elements degree of freedom should be strictly considered to observe real structural behaviour. The schematic representation of the frame is shown in Figure 8. The stiffness and damping coefficient values were taken from the experimental results of BRBE 350. For time history analysis, El Centro earthquake ground acceleration with a time interval of $0.02 \mathrm{sec}$ is applied to the bare frame with and without BRB. When the BRB was placed diagonally in the frame as shown in Figure 9, the maximum damping force of $61.84 \mathrm{kN}$ was developed. For the frame without BRBE, the maximum displacement observed was $14.1 \mathrm{~mm}$, while the same frame with BRBE was $7 \mathrm{~mm}$. There was also a displacement reduction of $50 \%$ due to the incorporation of the BRBE, as depicted in Figure 10.

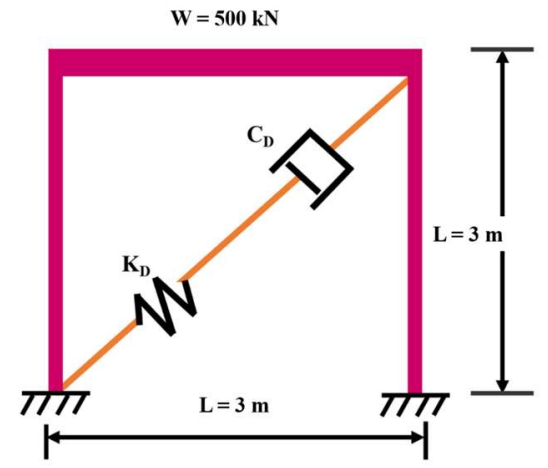

Fig. 8. Geometry of RCC frame

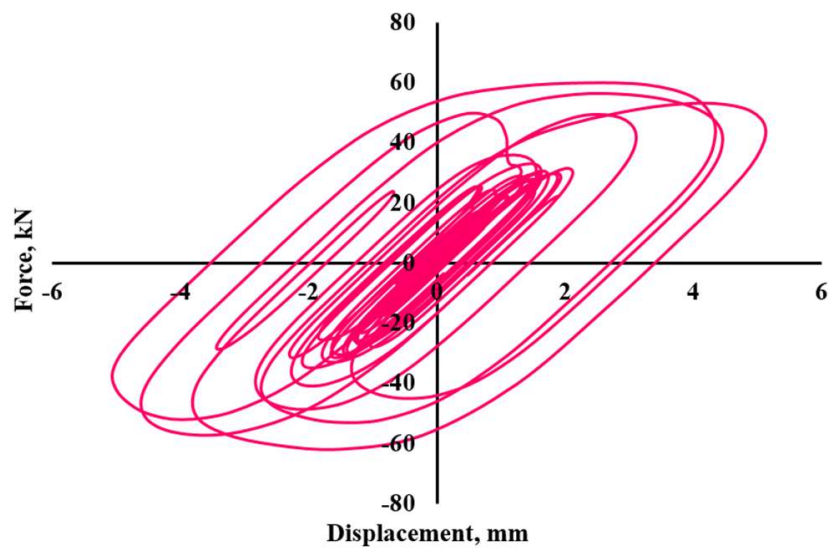

Fig. 9. Force vs. displacement (Numerical Simulation) 


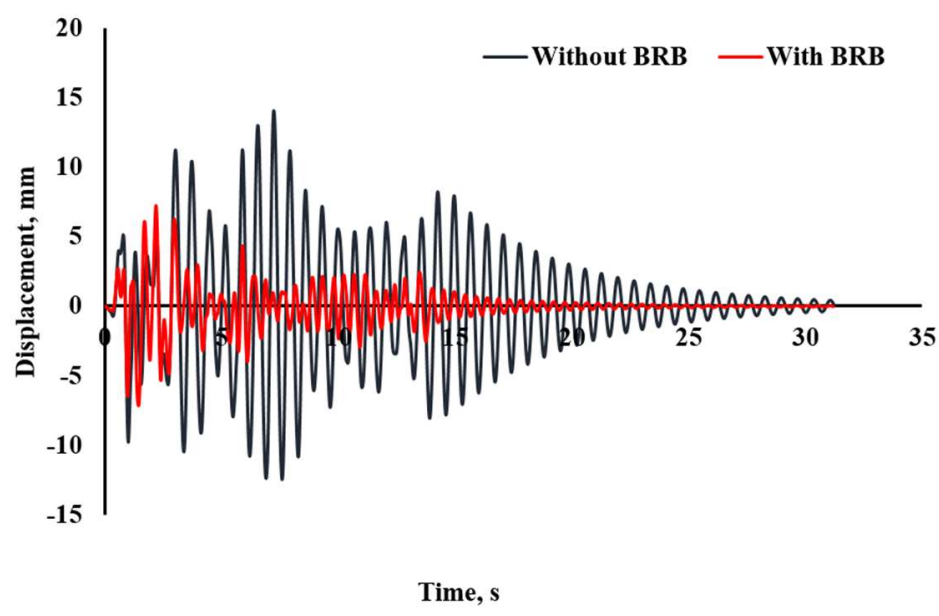

Fig. 10. Displacement vs. time with and without BRB

\section{CONCLUSION}

This paper presented a novel BRB (BRBE) with a debonded gap filled with EPS. The BRBE performed well structurally and helped in mitigating the effects of the seismic response on the RC frames. Further, it displayed a better strength-toweight ratio when compared to conventional BRBs with concrete as the restraining mechanism. Cyclic load tests were carried out on six specimens and the results were validated. The maximum load-carrying capacity of novel BRB was recorded as $62.2 \mathrm{kN}$ in experimental investigation. Also, this novel specimen displayed better resistance to core buckling, in addition to being more ductile, primarily due to the EPS packing. The outer steel core tube length influenced the performance of the BRBE. When this novel BRB was placed diagonally in a single-story RC frame, the load-carrying capacity improved, with the lateral displacement dropping by around $50 \%$. Therefore, this novel passive system is easy to prepare, cheaper than the conventional BRBs, and can be used as an effective energy dissipating device to control seismic vibration. In this way, it can substantially mitigate the effect of seismic responses in RC structures.

\section{REFERENCES}

1. Guo, LH, Jia, MM, Li, R and Zhang, SM 2013. Hysteretic analysis of thin steel plate shear walls, Int. J. Steel Structures", Vol. 13, No. 1, 163-174. 
2. Ji, XD, Cheng, XW, Jia, XF and Varma, AH. 2017. Cyclic in-plane shear behaviour of double-skin composite walls in high-rise buildings, Journal of Structural Engineering, Vol. 143, No. 6.

3. Han, LH, Li, YJ and Liao, FY 2011. Concrete-filled double skin steel tubular (CFDST) columns subjected to long-term sustained loading, Thin Walled Structure, Vol. 49, No. 12, 1534-1543.

4. Yang, YL, Wang, YY, Fu, F and Liu, JC 2015. Static behaviour of T-shaped concrete-filled steel tubular columns subjected to concentric and eccentric compressive loads, Thin-Walled Structure, Vol. 95, 374-388.

5. Wang, YY, Chen, P, Liu, CY and Zhang, Y 2017. Size effect of circular concrete-filled steel tubular short columns subjected to axial compression, Thin-Walled Structure, Vol. 120, 397-407.

6. Black, CJ, Makris, N and Aiken, ID 2004. Component testing seismic evaluation and characterization of buckling- restrained braces, Journal of Structural Engineering (ASCE), Vol. 130, No. 6, 880-894.

7. Amiria, J, Vaseghi, A, Mirza Goltabar Rowshana and Shafiei Seifabadi, H 2013. Effect of the height increasing on steel buildings retrofitted by buckling restrained bracing systems and TTD damper, International Journal of Engineering, Vol. 26, 1145-1154.

8. Sahoo, DR. and Chao, S-H 2010. Performance-based plastic design method for buckling-restrained braced frames, Engineering Structures, Vol. 32, No. 9, 2950-2958.

9. Jia, MM, Guo, LH and Lu, DG 2014. Performance testing and comparison of buckling-restrained braces with $h$ and crisscross cross-section unrestrained segments, Int. J. Steel Structures, Vol. 14, No. 9, 745-753.

10. Chou, CC and Chen, SY 2010. Sub-assemblage tests and finite element analyses of sandwiched buckling-restrained braces, Engineering Structures, Vol. 32, No. 8, 2108-2121.

11. Jia, MM, Yu, XH, Lu, DG and Lu, BB 2017. Experimental research of assembled buckling restrained braces wrapped with carbon or basalt fiber, J. Constr. Steel Research, Vol. 131, 144-161.

12. Akcelyan, Sarven, Dimitrios G. Lignos, and Tsuyoshi Hikino 2018. Adaptive numerical method algorithms for nonlinear viscous and bilinear oil damper models subjected to dynamic loading, Soil Dynamics and Earthquake Engineering, Vol. 113, 488-502.

Editor received the manuscript: 29.05.2019 